\section{BD6 Walnut}

\section{Géza Bujdosó}

National Agricultural Research and Innovation Center, Research Institute for Fruit Growing and Ornamentals, Budapest, 1223, Hungary

\section{Attila Fodor and Anita Karacs-Végh \\ Szent István University, Faculty of Horticultural Science, Department of Plant Pathology, Budapest, 1118, Hungary}

Additional index words. breeding, Hungary, Juglans regia, Xanthomonas arboricola pv. juglandis, walnut pomology

'BD6' is a novel bred genotype derived from the walnut breeding program of the Research Institute for Fruit Growing and Ornamentals located in Budapest, Hungary. Because of its early budbreaking date, it needs warmer and safe fruit site conditions (small hills instead of flat sites). Female flowers of 'BD6' start to bloom earlier than the male flowers. It has a good and regular crop because of its intermediate fruiting pattern. Early ripening 'BD6' can start the Hungarian walnut season in the near future. Because of its very low susceptibility to walnut blight (Xanthomonos arboricola pv. juglandis), it can also be recommended as a donor for different breeding programs.

\section{Origin}

Walnut breeding at the Research Institute for Fruit Growing and Ornamentals started with selections from the local population in 1950. Three terminal bearing cultivars (Alsószentiváni 117, Milotai 10, and Tiszacsécsi 83) were released from this stage of breeding. In addition to the selection from the local population, cross-breeding started in 1970 using the U.S.-bred 'Pedro' as the paternal parent because of its high productivity on lateral buds. There has been an important focus on late leafing, large yields on lateral buds, and good fruit quality (at least $32 \mathrm{~mm}$ in diameter, light shell and kernel color, smooth shell surface, at least $40 \%$ kernel ratio, good taste, no bitter flavor, and no aftertaste). Another five lateral bearing varieties (Milotai bötermő, Milotai kései ${ }^{\circledR}$, Milotai intenzív, Bonifác ${ }^{\circledR}$, and Alsószentiváni kései ${ }^{\circledR}$ ) were released from this stage

\footnotetext{
Received for publication 27 May 2020. Accepted for publication 15 June 2020 .

Published online 15 July 2020.

The research was supported by the National Research, Development and Innovation Office in the frame of "Walnut breeding in order to release new late leafing and lateral bearing cultivar(s)" Hungarian - Iranian project (project no. 123311). G.B. is the corresponding author. E-mail: bujdoso. geza@fruitresearch.naik.hu or resinfru@yahoo. com.

This is an open access article distributed under the CC BY-NC-ND license (https://creativecommons. org/licenses/by-nc-nd/4.0/).
}

of the research. These two methods of breeding are used in parallel during the current stage of the program (Bujdosó et al., 2016, 2019).

\section{Methods}

The experimental orchard was planted on chernozem soil with a high lime content $(\mathrm{pH}$, 8 ; total lime content in the top $60 \mathrm{~cm}$ layer, $5 \%$; humus content, $2.3 \%$ to $2.5 \%$; the Arany-type cohesion index $=40$, which refers to medium compactness) and established in Érd (lat. $47^{\circ} 20^{\prime} 11^{\prime \prime} \mathrm{N}$, long. $18^{\circ} 51^{\prime} 53^{\prime \prime} \mathrm{E}$, $127 \mathrm{~m}$ above sea level). Not only in Hungary but also in the whole Carpathian Basin, the most commonly grown 'Milotai 10' and the U.S.-bred standard cultivar Chandler were included in the trial as reference cultivars. All observed trees were grafted on Juglans regia selected seedlings, planted in three replications (four trees of each) of each for $10 \mathrm{~m}$ in the rows, with $10 \mathrm{~m}$ between the rows, and trained to a central leader canopy. The phenological and pomological characteristics were collected between 2010 and 2019. During this period, the average yearly temperature was $11.5{ }^{\circ} \mathrm{C}$, whereas the average yearly temperature during the growing season (between March and September) was $16.7{ }^{\circ} \mathrm{C}$, the number of days with frosts during spring (between March and May) was $5.4 \mathrm{~d}$ /year, the average yearly precipitation was $573.9 \mathrm{~mm}$, and the annual sunshine hours were $2079 \mathrm{~h}$.

Phenological and pomological traits (Table 1) of the cultivars included in the trial were evaluated using UPOV walnut descriptors (Anonymous, 2017). The yield efficiency was calculated as the cumulative yield/trunk cross-sectional area. Additionally, a new index called the cracking rate was introduced, which indicates the ratio of halves to the whole kernel weight. Susceptibility/resistance of the observed cultivars to walnut blight were described by Ozaktan et al. (2008) and Tsiantos et al. (2008). A comparison of cultivars using the spot diameter was performed using a univariate analysis of varby a cultivar effect. The normality of the defect members was checked using the Shapiro-Wilk test. Scattering homogeneity was confirmed by the Levene test. Pairwise iance model in which the factor is represented comparisons were made based on the Tukey test. The statistical program was the IBM SPSS Statistics 23.

\section{Description}

'BD6' is an unknown pedigree plant selected from the local population. It has an early leafing out time; therefore, spring frost-free site conditions are needed to cultivate on the commercial level. Its buds start to grow 4 to $5 \mathrm{~d}$ before 'Milotai 10' and 11 to $12 \mathrm{~d}$ before 'Chandler'. Its first male and female flowers open at similar times, similar to 'Milotai 10' and 'Chandler'. 'BD6' is protogynous like 'Milotai 10'. Approximately 35 to $45 \%$ of its female flowers appear on the lateral buds. This value is a bit higher compared with 'Milotai 10' (15\% to $20 \%$ ) but lower than that of 'Chandler' $(60 \%$ to $80 \%)$. 'Alsószentiváni 118 ', 'Tiszacsécsi 2', and 'Pedro' are the best pollenizers for 'BD6'. The harvest date of 'BD6' is $10 \mathrm{~d}$ before that of 'Milotai 10' and $20 \mathrm{~d}$ before that of 'Chandler', which means these cultivars can be the first ripening among the Hungarian cultivars. Considering the yield efficiency, 'BD6' is similar to 'Chandler', but the yields of both cultivars are higher than that of 'Milotai 10'. The tree and growth characteristics are similar to those of 'Milotai 10'. It is important to mention that, according to the results of our artificial infection trials performed during the past 4 years, 'BD6' has a high tolerance to walnut blight (Table 2, Supplemental Figs. 1-3). Nuts in the lateral view have an ovate shape, medium tip, and large width (roundness index of 'BD6' $=0.7$ ), but the standard cultivars have a round shape (roundness index of 'Milotai 10' and 'Chandler' $=0.9)$. Fruits of 'BD6' can reach the premium grade categories (average nut width of 'BD6' $=34.6 \mathrm{~mm}$; that of 'Milotai $10^{\prime}=33.2 \mathrm{~mm}$; that of 'Chandler' = $33.0 \mathrm{~mm}$ ). The 'BD6' has as light brown shell color similar to that of the standard cultivars. The fruits remove easily from the husk at optimal ripening stage. The shell has thickness similar to that of the standards (1.6 $\mathrm{mm}$ for 'BD6' and 'Chandler' and $1.5 \mathrm{~mm}$ for 'Milotai 10') and is slightly grooved, similar to 'Milotai 10'. The shell strength is intermediate for all three cultivars. The nut weight of 'BD6' is heavier, with differences of $29 \%$ and $37 \%$ compared with 'Milotai 10' and 'Chandler', respectively. The kernel is large and the color of the kernel is light amber. The kernel weight is $18 \%$ and $33 \%$ larger than that of 'Milotai 10 ' and 'Chandler', respectively. Its kernel percentage is similar to that of the standard cultivars mentioned here. The cracking index of 'BD6' $(68.6 \%)$ is similar to that of 'Milotai 10' (73.2\%). Although removing the kernel is easy for the two comparative cultivars, it is medium for 'BD6' due to the medium thickness of the dividing membranes (Table 1, Fig. 1). Different organoleptic testing was performed to collect more detailed information about the nut and 
Table 1. Nut and kernel traits of 'BD6' compared with 'Milotai 10' and 'Chandler'.

\begin{tabular}{lccc}
\hline Trait & BD6 & Milotai 10 & Chandler \\
\hline Nut height $(\mathrm{mm})$ & $46.8 \pm 2.3$ & $36.7 \pm 2.7$ & $38.3 \pm 1.9$ \\
Nut width $(\mathrm{mm})$ & $34.6 \pm 1.4$ & $33.2 \pm 2.3$ & $33.0 \pm 1.7$ \\
Nut thickness $(\mathrm{mm})$ & $37.1 \pm 2.0$ & $34.8 \pm 2.0$ & $33.6 \pm 1.8$ \\
Roundness index $(\mathrm{mm})$ & $0.70 \pm 0.03$ & $0.90 \pm 0.03$ & $0.90 \pm 0.04$ \\
Shell color & Light brown & Light brown & Light brown \\
Shell surface & Slightly grooved & Slightly grooved & Moderately grooved \\
Shell thickness $(\mathrm{mm})$ & $1.6 \pm 0.2$ & $1.5 \pm 0.2$ & $1.6 \pm 0.2$ \\
Shell strength & Intermediate & Intermediate & Intermediate \\
Nut weight $(\mathrm{g})$ & $16.3 \pm 2.7$ & $12.6 \pm 2.4$ & $11.9 \pm 1.2$ \\
Kernel weight $(\mathrm{g})$ & $7.1 \pm 1.7$ & $5.8 \pm 1.4$ & $5.5 \pm 0.9$ \\
Kernel percentage (\%) & $40.0 \pm 6.2$ & $45.0 \pm 7.9$ & $50.3 \pm 5.1$ \\
Cracking index $(\%)$ & $68.6 \pm 11.4$ & $73.2 \pm 14.0$ & $86.7 \pm 11.1$ \\
Ease of kernel removal & Medium & Easy & Very easy \\
Kernel color & Light amber & Light & Light \\
\hline
\end{tabular}

${ }^{\mathrm{z}}$ Dates are 10 years (2010-19). Data are presented as means \pm SD.

Table 2. Tree and phonological characteristics of 'BD6' compared with 'Milotai 10' and 'Chandler'.

\begin{tabular}{lccc}
\hline Trait & BD6 & Milotai 10 & Chandler \\
\hline Date of budbreak & 30 Mar. $\pm 8.9 \mathrm{~d}$ & 7 Apr. $\pm 10.6 \mathrm{~d}$ & $15 \mathrm{Apr} . \pm 10.0 \mathrm{~d}$ \\
First male bloom date & $23 \mathrm{Apr} . \pm 9.5 \mathrm{~d}$ & $27 \mathrm{Apr} . \pm 5.3 \mathrm{~d}$ & $22 \mathrm{Apr} . \pm 4.7 \mathrm{~d}$ \\
First female bloom date & 21 Apr. $\pm 10.6 \mathrm{~d}$ & 19 Apr. $\pm 7.8 \mathrm{~d}$ & $29 \mathrm{Apr} . \pm 3.7 \mathrm{~d}$ \\
Ratio of female flowers on lateral buds (\%) & $35-45$ & $15-25$ & $60-80$ \\
Dichogamy & Protogynous & Protogynous & Protandrous \\
Harvest date & 7 Sept. $\pm 6.0 \mathrm{~d}$ & 17 Sept. $\pm 6.8 \mathrm{~d}$ & $27 \mathrm{Sept} . \pm 5.9 \mathrm{~d}$ \\
Yield efficiency $\left(\mathrm{kg} / \mathrm{cm}^{2}\right)$ & $0.34 \pm 0.04$ & $0.28 \pm 0.05$ & $0.37 \pm 0.06$ \\
Tree vigor & Intermediate & Intermediate & Intermediate \\
Growth habit & Semi-erect & Semi-erect & Semi-erect \\
Branching & Semi-dense & Semi-dense & Dense \\
Susceptibility to walnut blight & Moderately resistant & High susceptibility & Moderately susceptible
\end{tabular}

${ }^{\mathrm{z}}$ Dates are 10 years (2010-19). Data are presented as means \pm SD.

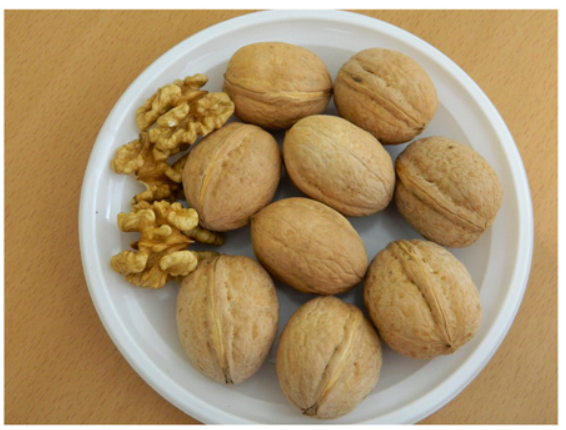

Fig. 1. Nuts of 'BD6' walnut.

kernel characteristics of 'BD6' (unpublished data). In the categories of nut size, shell color, shell surface, and kernel color, 'BD6' was always among the top three ranked cultivars.

\section{Availability}

'BD6' was registered on the National List of Cultivars in 2019. Propagation trials testing "traditional" hand grafting propagation started in 2016 . It is easy to make hand graftings with 'BD6'. Success producing grafted 'BD6' trees is similar to that of other cultivars. 'BD6' is in the stage of propagation. Virus-free material is available in the nuclear stock of the Research Institute. Ex situ multisite trials to test this genotype in different climate conditions have been established not only in Hungary but also in the southern part of the Slovak Republic and the BadenWürttemberg Federal State of Germany since 2016.

\section{Literature Cited}

Anonymous. 2017. Guidelines for the conduct of tests for distinctness, uniformity, and stability. (TG/125/5proj5) International Union for the Protection of New Varieties of Plants. UPOV. Geneva, Switzerland. 18$22 \mathrm{p}$.

Bujdosó, G., E. Kónya, M. Berki, M. NagyGasztonyi, K. Bartha-Szügyi, B. Marton, F. Izsépi, and N. Adányi. 2016. Fatty acid composition, oxidative stability, and antiox- idant properties of some Hungarian and other Persian walnut cultivars. Turk. J. Agr. For. $2: 160-168$

Bujdosó, G., S. Gandev, F. Izsépi, K. SzügyiBartha, and Gy. Végvári. 2019. Detection and quantification of some phenolic compounds in kernel of selected Hungarian and Bulgarian Persian walnut cultivars. Eur. J. Hort. Sci. 2:85-90.

Ozaktan, H., M. Erdal, A. Akkopru, and E. Aslan. 2008. Evaluation of susceptibility of some walnut cultivars to Xanthomonas arboricola pv. juglandis by immature nut test. COST873 Management Committee Meeting, 20-23 Oct. 2008, Athens, Greece. (abstr.), p. 29. 5 May 2020. <https://www.yumpu.com/en/document/ $\mathrm{read} / 49436181$ information-on-apical-necrosis-of-walnut-in-turkey-cost-873>.

Tsiantos, J., I.K. Vagelas, C.I. Rumbos, A. Chatzaki, D. Rouskas, and F.T. Gravanis. 2008. Evaluation of resistance of cultivated walnut varieties and selections to Xanthomonas arboricola pv. juglandis in Greece. COST873 Management Committee Meeting, 20-23 Oct. 2008, Athens, Greece. (abstr.), p. 27. 5 May 2020. <https://www.yumpu.com/en/document/ read/49436181/information-on-apical-necrosis-of-walnut-in-turkey-cost-873>. 


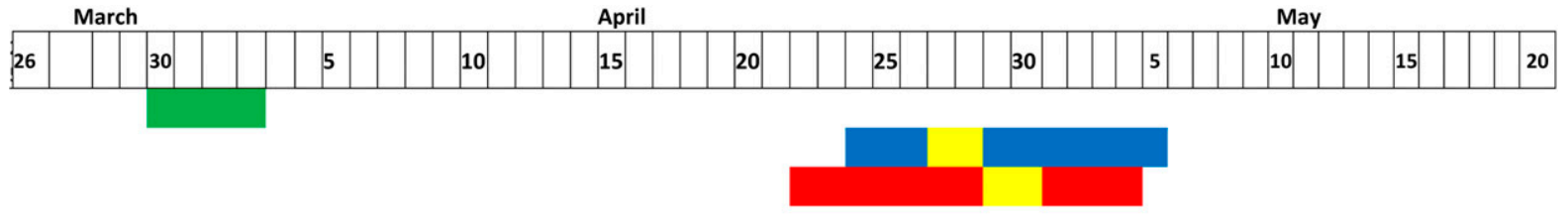

Milotai 10
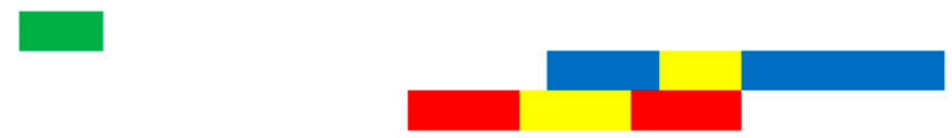

Chandler

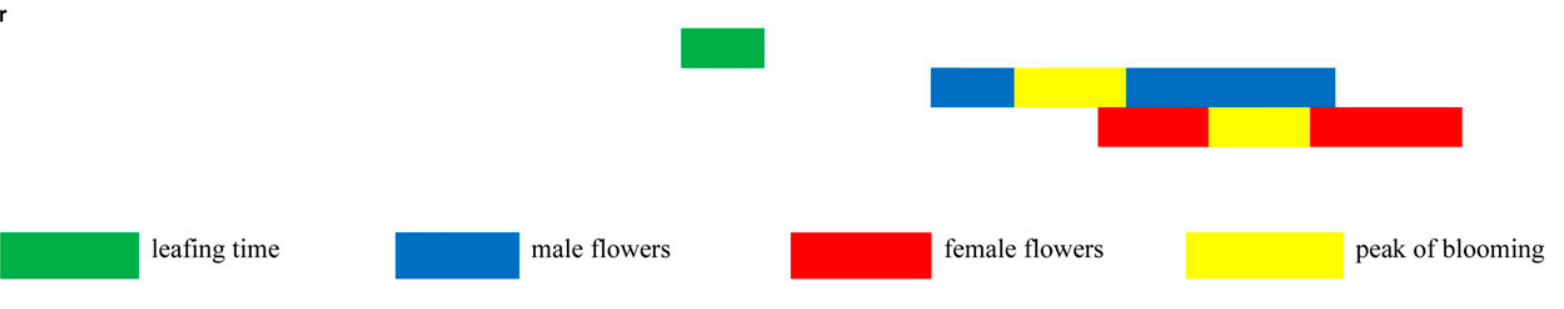

Supplemental Fig. 1. Phenogram of leafing date, pistillate receptivity, and pollen shedding period of 'BD6' compared with 'Milotai 10' and 'Chandler'.

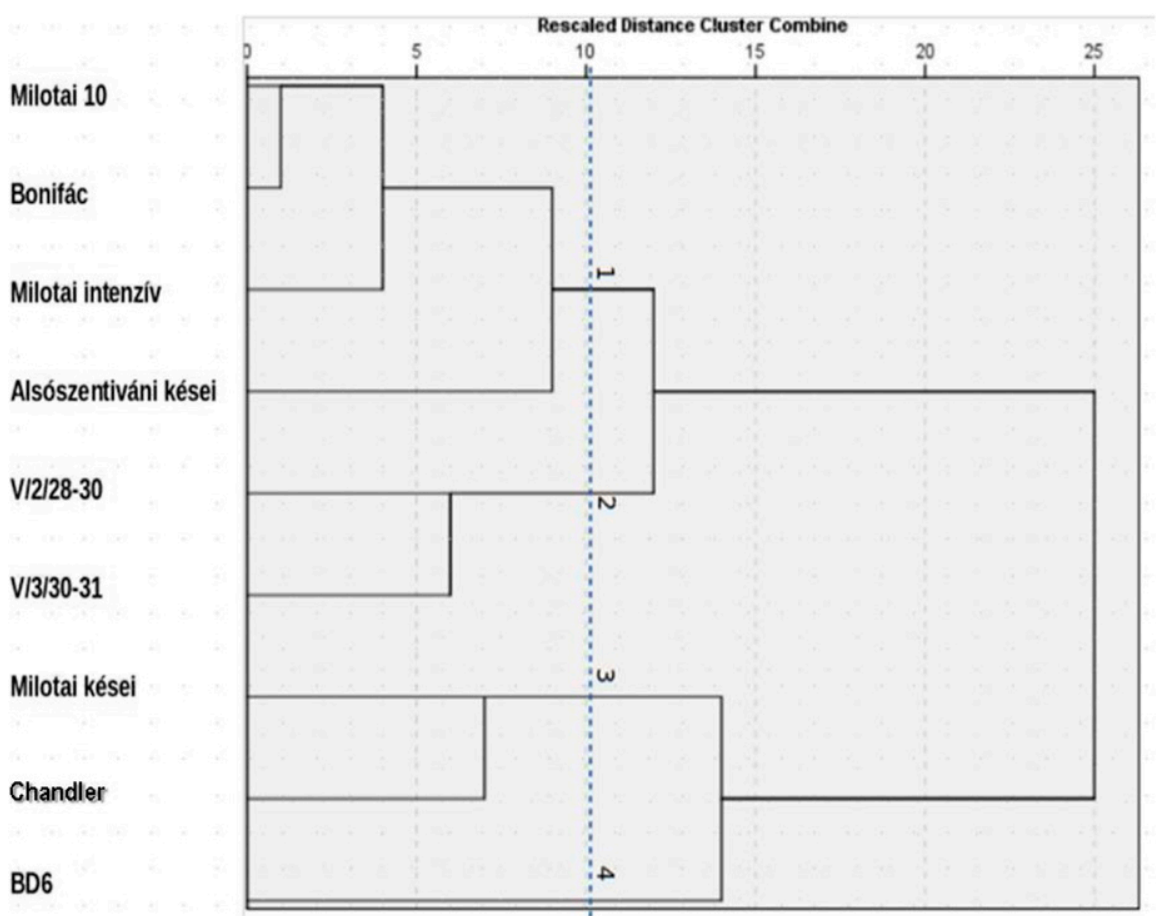

Supplemental Fig. 2. Dendrogram of 'BD6' compared with standard cultivars Milotai 10 and Chandler (four groups were formed: 1, highly susceptible; 2, susceptible; 3, moderately susceptible; 4, moderately resistant). 


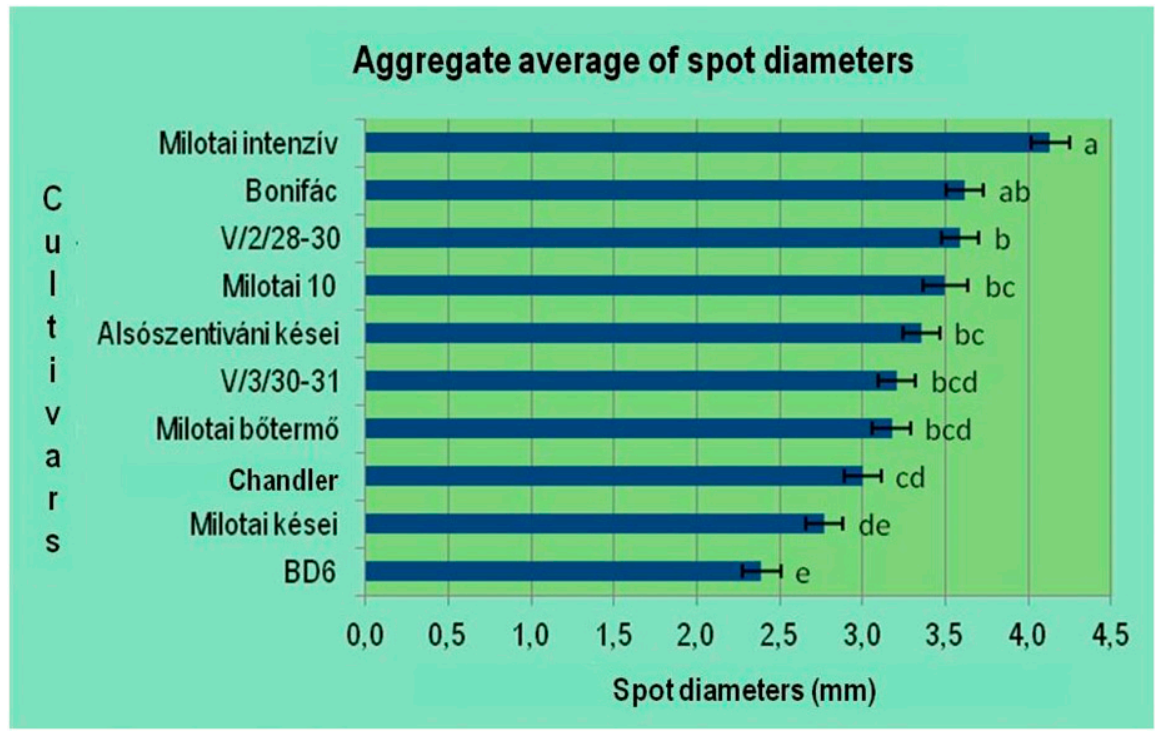

Supplemental Fig. 3. Aggregate average of spot diameters of the cultivars involved in the trial (2016-19). 